Fincham, J. R. S. \& Boylen, J. B. (1957). J. gen. Microbiol. 16, 438-448

\title{
Neurospora crassa Mutants Lacking Argininosuccinase
}

\author{
BY J. R. S. FINCHAM AND JOYCE B. BOYLEN \\ Department of Genetics, University College of Leicester
}

SUMMARY: Four mutant strains of Neurospora crassa, due to repeated mutation within the same short chromosome region, required arginine as a nutrient and failed to respond to citrulline. These strains accumulated argininosuccinic acid in the mycelium when grown on a medium supplemented with arginine. When the medium also contained citrulline this accumulation of argininosuccinic acid was enhanced, and citrulline also accumulated in the mycelium. Citrulline depressed the growth of the mutants at a concentration at which it had no effect on growth of the wild type.

Cell-free extracts of the wild type contained an argininosuccinase which catalysed the reversible splitting of argininosuccinic acid to arginine and fumaric acid. A procedure is described for the approximately fivefold purification of the enzyme. The pH optimum for the synthesis of argininosuccinic acid from arginine and fumaric acid was close to $\mathrm{pH} \mathbf{7 \cdot 0}$.

Neither cell-free extracts nor partially purified preparations from the four mutants showed any trace of argininosuccinase activity ; 1-2 \%, and $0 \cdot 2 \%$, of normal wild-type activity should have been detectable in crude cell-free extracts and purified preparations, respectively. Neither the argininosuccinase activity of crude wild-type extracts, nor that of the partially purified preparations was appreciably altered by the addition of corresponding preparations from one of the mutants. A mixture of wild-type and mutant mycelium extracted together yielded the amount of activity to be expected on the assumption that the mutant mycelium was neither contributing to, nor decreasing, the yield.

Arginase and fumarase activities were similar in the wild type and one of the mutants.

The great majority of nutritionally exacting mutants of Neurospora crassa and other micro-organisms are enabled to grow by the addition to the minimal medium of a single substance. This has suggested that 'a large class of genes exist in which each gene controls the synthesis of, or the activity of, but a single enzyme' (Hørowitz, 1950). Mutants which require arginine or one of its precursors (Srb \& Horowitz, 1944) have long provided one of the mostquoted examples of a series of mutational 'blocks' in a biosynthetic sequence, but a more direct verification of the interpretation through an investigation of the enzymes involved has not, until recently, been possible. Recent work by Ratner and her collaborators (Ratner \& Petrack, 1953 $a, b$; Ratner, Petrack \& Rochovansky, 1953; Ratner, Anslow \& Petrack, 1953) has elucidated the mechanism of the conversion of citrulline to arginine in liver and kidney, and suggested the possibility of parallel investigations on some of the argininerequiring Neurospora mutants. The present study is concerned with a class of mutants located in linkage group VII (Newmeyer, 1957). Preliminary experiments by Dr Dorothy Newmeyer (personal communication) suggested that these mutants were 'blocked' in the terminal step in arginine synthesis, the splitting of argininosuccinic acid to give arginine and fumaric acid. The enzyme catalysing this reaction, which was called the splitting enzyme by Ratner, will be referred to in the present paper as argininosuccinase. 


\section{METHODS}

Strains. The wild-type strain ST $A$ of Neurospora crassa, and the argininerequiring mutant strains $\mathrm{B317}, \mathrm{B} 362, \mathrm{~B} 368$ and $\mathrm{B370}$ were supplied by Dr Dorothy Newmeyer, and were the same as those used in her parallel genetic investigation (Newmeyer, 1957). In a few experiments the genetically and biochemically distinct arginine-requiring mutant 36703, re-isolated in this laboratory from an ascospore, was used.

Culture methods. The minimal medium used throughout was Fries no. 3 (composition given in Fincham, 1954). For growth of the mutants (and also of the wild type where comparisons between wild type and mutant were being made) it was supplemented with L-arginine monohydrochloride to $2 \cdot 5 \times 10^{-3} \mathrm{M}$. Cultures were grown from conidial inocula without agitation at $25^{\circ}$. Mycelium for enzyme extraction was grown in culture flasks each containing $150 \mathrm{ml}$. of medium at a depth of about $1 \mathrm{~cm}$., while in other experiments 15 or $40 \mathrm{ml}$. media in 100 and $250 \mathrm{ml}$. flasks, respectively, were used.

Identification of amino acids in mycelial extracts. Mycelial pads were washed with water, sucked as dry as possible on a Buchner funnel, and extracted with their own weight of $0.03 \mathrm{M}$-phosphate buffer $\left(\mathrm{pH} 7.5\right.$ ) for $10 \mathrm{~min}$. at $100^{\circ}$. Samples $(2 \mu \mathrm{l}$.) of the resulting extracts were applied to Whatman no. 1 paper sheets and the chromatograms developed for $8 \mathrm{hr}$. with phenol saturated with water in the presence of ammonia vapour. The papers were dried at room temperature and coloured with ninhydrin in the usual way. Provisional conclusions drawn from the phenol chromatograms were checked by twodimensional chromatography using butanol + acetic acid (100 n-butanol:24 glacial acetic acid:100 water, by vol.; upper phase) as the second solvent. Identifications of the major amino acid spots were made by two-dimensional chromatography of samples of the unknowns with and without the addition of appropriate amounts of known amino acids.

Preparation and estimation of argininosuccinic acid. Barium argininosuccinate was prepared from arginine and fumarate with partially purified pig kidney enzyme as described by Ratner, Petrack \& Rochovansky (1953). The barium salt was converted to the potassium salt, which was standardized by reference to leucine by the quantitative ninhydrin procedure of Moore \& Stein (1948). Assuming two equivalents of barium, the product was $65 \%$ pure and, from its absorption at $240 \mathrm{~m} \mu$, appeared to contain a molecular proportion of $10 \%$ of fumaric acid. No amino acid impurities were revealed on phenol water chromatograms; the argininosuccinic acid gave a compact spot at $\boldsymbol{R}_{\boldsymbol{F}} \mathbf{0 \cdot 2 7}$. Argininosuccinic acid formed enzymically in experimental reaction. mixtures was separated from arginine and ornithine (the only other amino acids present in appreciable concentration) on phenol chromatograms. It was determined quantitatively by scanning the argininosuccinic acid region of each sheet parallel to the solvent front with an EEL scanner (made as part of the EEL electrophoresis apparatus; Evans Electroselenium Ltd., Harlow, Essex) and comparing the heights of the peaks on the scanning diagram with a standard curve obtained from a series of argininosuccinate standards run on the 
same sheets as the unknowns. The method was essentially the same as described elsewhere (Fincham \& Boulter, 1956) for glutamic acid except that scanner readings were corrected individually by subtracting the average reading given by the blank paper on each side of each spot. The error of the method was not greater than $5 \%$ for concentrations of argininosuccinate of $6 \times 10^{-3} \mathrm{M}$ or more, and a concentration of $10^{-4} \mathrm{M}$ could be easily detected by superimposing samples three times on the same spot.

Other analytical procedures. Citrulline was determined by the method of Archibald (1944) with the omission of the procedures designed to get rid of allantoin and urea. It was found that incubation of mycelial extracts or used medium with urease made no difference to the results; extracts of mycelium which had not been grown in the presence of citrulline contained no substances reacting to give a colour with diacetyl monoxime.

Protein was determined by the quantitative biuret method previously described (Fincham, 1954).

Ammonia was determined by microdistillation in Conway units, followed by nesslerization.

$\mathrm{pH}$ values were measured with a glass electrode.

Enzyme assays. Argininosuccinase was determined by measuring the argininosuccinic acid produced from arginine and fumaric acid in the following system: $0.05 \mathrm{M}$-sodium fumarate; $0.05 \mathrm{M}$-L-arginine monohydrochloride; 0.025 M-phosphate $\left(\mathrm{Na}_{2} \mathrm{HPO}_{4}+\mathrm{KH}_{2} \mathrm{PO}_{4}\right)$ at $\mathrm{pH} 7.5 ; 0.2 \mathrm{ml}$. enzyme solution in a total vol. of $0.8 \mathrm{ml}$.; temp. $35^{\circ}$. The reaction was stopped by brief heating to $100^{\circ}$, duplicate (or, in critical experiments, quadruplicate) samples were applied to chromatograms, and argininosuccinic acid determined by the method described above. In experiments designed to detect traces of enzyme activity, control tubes lacking fumarate were set up, and the small amount of apparent argininosuccinic acid in the control (due to a very faint background streak apparently deriving from the enzyme preparation) was subtracted from the corresponding value for the complete system in each case. A possible weakness of the method, especially when used to assay crude extracts, is that arginine and fumarate concentrations will tend to be decreased by arginase and fumarase. It was found, however, that either arginine or fumarate could be decreased in concentration by at least $60 \%$ without appreciably affecting the rate of argininosuccinic acid formation during the incubation periods usually used. The fact that argininosuccinic acid formation was nearly proportional to enzyme concentration even in the case of crude extracts (Table 3) indicated that there was probably always a sufficient excess of substrate.

Fumarase was determined by following the disappearance of fumaric acid in a Unicam ultraviolet spectrophotometer at $240 \mathrm{~m} \mu$. (Racker, 1950).

Arginase was determined qualitatively by observing the appearance of ornithine on chromatograms, or quantitatively by determination of ammonia after treatment of digests with excess urease (Fig. 7). The urease was obtained from L. Light and Co. (Colnbrook, Bucks.), and was free from arginase.

Enzyme preparations. For the preparation of cell-free extracts, mycelium from $48 \mathrm{hr}$. cultures was homogenized with 5-10 times its wet weight of 
0.02 M-phosphate $\left(\mathrm{KH}_{2} \mathrm{PO}_{4}+\mathrm{Na}_{2} \mathrm{HPO}_{4} ; \mathrm{pH} 7.5\right)$ either in an 'Atomix' blender or, in most experiments, in a mortar with powdered glass, and the blend was filtered through kieselguhr to remove cell-wall fragments and particles, as previously described (Fincham, 1954). The filtrate was usually dialysed for 2-3 hr. with stirring, against two changes of the same buffer as used in the extraction.

The following procedure, based partly on unpublished information from Dr Newmeyer and partly on Ratner's method for the pig kidney enzyme, was used to obtain an approximately five-fold purification (with respect to protein) of argininosuccinase from the crude extract. Solid ammonium sulphate $(7 \mathrm{~g}$.) was added to $20 \mathrm{ml}$. of crude extract to give $50 \%$ saturation. This and subsequent ammonium sulphate additions were made over a $15-20 \mathrm{~min}$. period with stirring, the temperature being kept near $0^{\circ}$. The resulting precipitate was collected by centrifugation at $3000 \mathrm{~g}$ for $10 \mathrm{~min}$. and taken up in $20 \mathrm{ml}$. of water. The solution was brought to $c . \mathrm{pH} 5.5$ by the addition of $1.7 \mathrm{ml}$. $0 \cdot 1 \mathrm{M}-\mathrm{KH}_{2} \mathrm{PO}_{4}$, heated to $51^{\circ}$ by immersion, with constant stirring, in a $60^{\circ}$ water bath (this took about $3 \mathrm{~min}$.) and cooled in an ice bath. Centrifugation at this stage seemed to be of no advantage. The $\mathrm{pH}$ value was brought back to c. $7 \cdot 5$ by the addition of $8 \cdot 3 \mathrm{ml} .0 \cdot 1 \mathrm{M}-\mathrm{Na}_{2} \mathrm{HPO}_{4}$ and solid ammonium sulphate was added as before to $30 \%$ saturation. The fairly bulky precipitate, containing much protein denatured during the heat step, was removed by centrifugation and the supernatant fluid was brought to $55 \%$ saturation with ammonium sulphate. The precipitate was centrifuged down, taken up in $1 \mathrm{ml}$. of $0.02 \mathrm{M}$-phosphate buffer ( $\mathrm{pH} 7 \cdot 5$ ), dialysed with stirring for $2-3 \mathrm{hr}$. against two changes of the same buffer, and recentrifuged. The slight precipitate was discarded. The supernatant fluid contained $10-15 \%$ of the original protein of the crude extract and about $50-60 \%$ of the original argininosuccinase activity. Most of the arginase and fumarase activities were removed by the first precipitation and the heat step. The final preparation contained not more than $2 \%$ of the original degree of fumarase activity and a variable amount of arginase activity ranging from nearly zero up to about $20 \%$ of that originally present. This preparation was often kept frozen overnight without apparent loss of activity.

\section{RESULTS}

Growth responses to arginine and to argininosuccinic acid

The mutants B317, B362, B368 and B370 were practically identical in their responses to arginine (Fig. 1). At lower arginine concentrations the amount of growth made was proportional to the amount of arginine present. An optimum concentration of arginine was $2.5 \times 10^{-3} \mathrm{M}$, and this was adopted for routine growth of the mutants. At this concentration of arginine growth of the mutants was closely similar to that of the wild type, both in weight of mycelium (Table 1) and in the final $\mathrm{pH}$ value of the medium (4.65-4.70 after 2 days for both the mutants and wild type in one experiment). Neither strain B362 nor strain $\mathbf{3 6 7 0 3}$ (which produces normal amounts of argininosuccinase) showed more than an unweighable trace of growth on minimal medium supplemented with 
potassium argininosuccinate at concentrations ranging from $10^{-3} \mathrm{M}$ to $5 \times 10^{-3} \mathrm{M}$.

Table 1. Inhibition of mutant strains of Neurospora crassa by citrulline

Growth for $64 \mathrm{hr}$. at $25^{\circ}$ in $15 \mathrm{ml}$. media. Dry weights to the nearest $\mathrm{mg}$. Concentrations of amino acids $2.5 \times 10^{-3} \mathrm{M}$ in each case.

\begin{tabular}{lrrrrrr}
$\begin{array}{l}\text { Wild } \\
\text { type }\end{array}$ & B B62 & $\begin{array}{l}\text { Wild } \\
\text { type }\end{array}$ & B317 & B362 & B 368 & B 370 \\
\multicolumn{5}{c}{ Amount of growth (mg. dry } & wt.) \\
$\overbrace{58}^{\text {Expt. 1 }}$ & 0 & 57 & 0 & 0 & 0 & 0 \\
57 & 53 & 64 & 61 & 52 & 55 & 54 \\
63 & 39 & 66 & 45 & 45 & 46 & 35
\end{tabular}

\section{Accumulation of argininosuccinic acid by mutant mycelium}

Two-dimensional chromatograms of extracts of wild-type mycelium grown on minimal medium showed a rather consistent pattern of amino acid spots which was not obviously altered by supplementation of the medium with either L-arginine or arginine $+\mathrm{L}$-citrulline (each amino acid at $2.5 \times 10^{-3} \mathrm{M}$ ). The main amino acids present were alanine, glutamic acid and glutamine; several other amino acids were generally present in much lower concentration.

Extracts of the mutant strains B317, B362, B368 and B370 grown on arginine-supplemented medium contained, in addition to the usual amino acids of the wild-type extracts, another major constituent which was identified as argininosuccinic acid. Mycelium of all four mutant strains grown in medium supplemented with both arginine and citrulline showed a strikingly different amino acid pattern. The main acids present were citrulline and argininosuccinic acid, the latter in considerably higher concentration than in mutant mycelium grown without the citrulline supplement. Alanine, glutamic acid and glutamine were all very much decreased in concentration in comparison with extracts of wild-type mycelium, and were often barely detectable. The results of a typical experiment in which one of the mutant strains was compared with wild type are shown in Fig. 2.

It seemed of some interest to determine whether all the citrulline added to mutant cultures could be accounted for at the end of growth either as residual citrulline or as argininosuccinic acid. In one experiment $100 \mu$ mole of L-citrulline was added to $40 \mathrm{ml}$. of medium which was also supplemented with arginine. After $65 \mathrm{hr}$. of growth $\mathrm{B362}$ mycelium (c. $77 \mathrm{mg}$. dry weight) was found to contain $18 \mu$ mole of citrulline and 15-20 $\mu$ mole (determined by visual comparison with standards on chromatograms) of argininosuccinic acid. The medium contained $56 \mu$ mole of citrulline and no detectable argininosuccinic acid (although up to $c$. $10 \mu$ mole might have been present without being detected on the chromatograms). These figures indicate an accumulation and retention of both amino acids by the mycelium against considerable concentration gradients. A parallel control culture without the citrulline supplement accumulated rather less than $5 \mu$ mole of argininosuccinic acid in the mycelium 
and no detectable citrulline either in the medium or the mycelium. Thus although some relatively slight utilization or degradation of the citrulline supplied was not excluded, at least some $85-90 \%$ of the citrulline added could be accounted for, either as citrulline or as argininosuccinic acid.

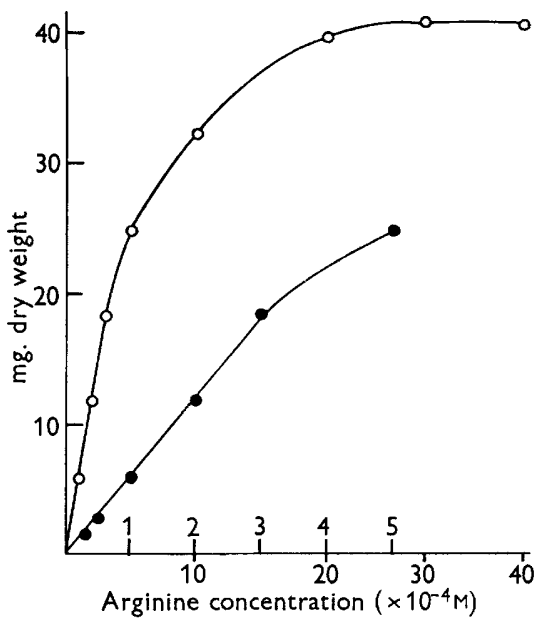

Fig. 1

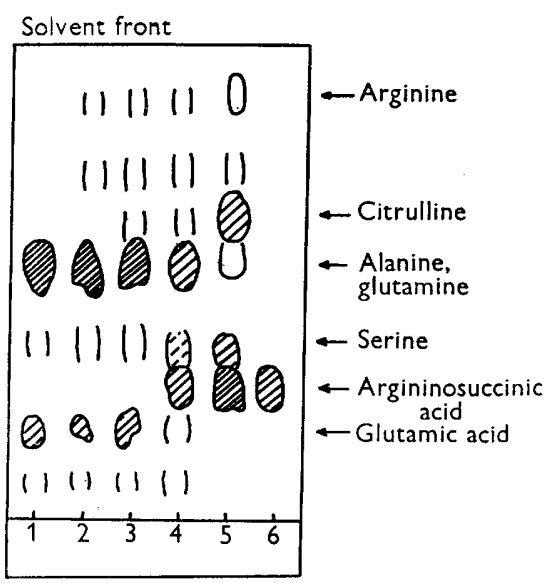

Fig. 2

Fig. 1. Response of Neurospora crassa mutant strain B362 to arginine. Growth for $63 \mathrm{hr}$. at $25^{\circ}$ in $15 \mathrm{ml}$. media. The weights shown are averages of duplicates. Open circles refer to the lower arginine concentration scale, and solid circles to the upper scale. Mutants B317, B368 and B370 gave the same curve to within experimental error.

Fig. 2. Phenol water chromatograms of mycelial extracts from (1) wild type grown on minimal medium; (2) wild type on minimal + arginine; (3) wild type on minimal+arginine+citrulline; (4) mutant $\mathrm{B362}$ on minimal+arginine; (5) mutant $\mathrm{B362}$ on minimal + arginine + citrulline; (6) $5 \times 10^{-3} \mathrm{M}$ argininosuccinate. Relative densities of the major spots are roughly indicated by cross-hatching; faint and streaky spots are not cross-hatched. The arrows indicate the positions of markers. The spots in the alanine region are due to roughly equal amounts of alanine and glutamine; the spot in the serine position in (5) is due partly to an unknown amino acid having a much lower $R_{F}$ value in butanol+ acetic acid than has serine. Mutants B317, B368 and B370 gave essentially similar results.

\section{Characteristics of argininosuccinase from wild type mycelium}

Dialysed cell-free extracts of wild-type mycelium could always be shown to contain an argininosuccinase. The presence of arginine in the medium was not found to have any effect on the production of the enzyme. The fractionation procedure already described resulted in an increase in argininosuccinase activity per unit wt. of protein of about five-fold, and, at the same time, generally decreased the arginase and fumarase activities to low values. The effectiveness of the procedure did not appear to be affected by the presence of arginine in the medium used for growing the mycelium. The $\mathrm{pH}$ optimum for synthesis of argininosuccinic acid was near $7 \cdot 0$ (Fig. 3). An attempt was made to determine the approximate Michaelis constants for arginine and fumaric acid, but these appeared to be too low to be conveniently determined by the present methods. When either arginine or fumaric acid was decreased in 
concentration to $0.01 \mathrm{M}$ argininosuccinic acid formation still proceeded at well over half the maximal rate. Thus the Neurospora enzyme appeared to have a higher affinity for both substrates than did the liver enzyme studied by Ratner, Anslow \& Petrack (1953). With a partially-purified preparation in which fumarase activity was low it was possible to follow fumaric acid formation from argininosuccinic acid by making use of its absorption in the ultraviolet (Ratner \& Petrack, 1953b). As would be expected from the value of the

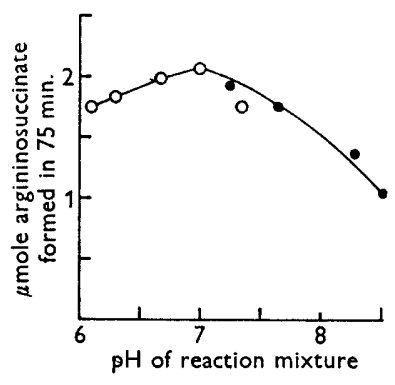

Fig. 3

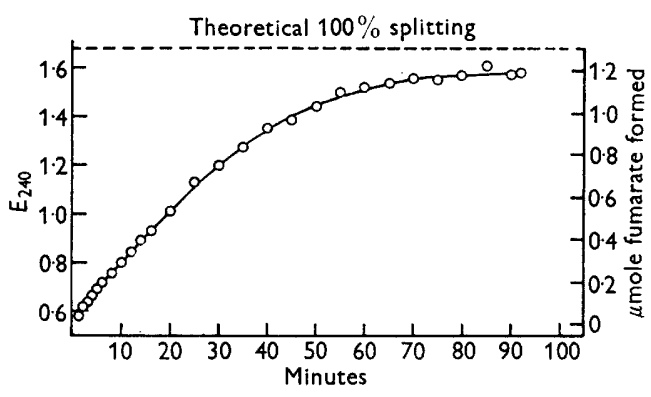

Fig. 4

Fig. 3. Dependence of argininosuccinic acid formation on $\mathrm{pH}$ value. Reaction mixtures contained, in $0.4 \mathrm{ml}$. : $20 \mu$ mole sodium fumarate; $10 \mu$ mole phosphate $(O)$ or borate $(\odot)$; $20 \mu$ mole $\mathbf{L}$-arginine monohydrochloride; $0.2 \mathrm{mg}$. protein of partially purified argininosuccinase from wild type. Temperature $35^{\circ}$.

Fig. 4. Splitting of argininosuccinate by a partially purified enzyme preparation. Spectrophotometer $(1 \mathrm{~cm}$.) cell contained, in $2 \cdot 7 \mathrm{ml} .: 50 \mu$ mole phosphate $(\mathrm{pH} 7.5) ; 1.6 \mathrm{mg}$. protein; and (added at time 0 ) $1.3 \mu$ mole potassium argininosuccinate. The right-hand scale shows $\mu$ mole fumarate formed on the assumption that the increase in optical density is due to fumarate formation. Temperature $c .18^{\circ}$.

equilibrium constant of the reaction determined by Ratner, Petrack \& Rochovansky (1953), the splitting of argininosuccinic acid proceeded almost to completion at the low concentration used in this experiment (Fig. 4). One partially purified enzyme preparation was found to catalyse argininosuccinic acid splitting at the rate of $1 \cdot 1 \mu \mathrm{mole} / \mathrm{hr} . / \mathrm{mg}$. protein at $18^{\circ}$ with an argininosuccinate concentration of $0.75 \times 10^{-3} \mathrm{M}$, and argininosuccinic acid formation at the rate of $4.0 \mu \mathrm{mole} / \mathrm{hr} . / \mathrm{mg}$. protein at $35^{\circ}$ with arginine and fumarate concentrations of $0.05 \mathrm{M}$.

\section{Absence of argininosuccinase in the mutants}

Table 2 shows the results of one of several experiments in which argininosuccinase activities of wild-type preparations were compared with those of corresponding preparations from mutant mycelium. Neither crude extracts of the mutants, nor mutant preparations which had been fractionated by the same procedure as gave a fivefold increase in wild-type enzyme activity, showed any trace of activity. In the experiment recorded in Table $2,2 \%$ of the activity found in the wild type should have been detectable in the crude extracts of the mutants had it been present, while as little as $0.2 \%$ of wild-type activity should have been detectable in the case of the partially purified preparations. 
Table 2. Argininosuccinase assays on crude and partially-purified preparations from mutants and wild type Neurospora crassa

Reaction mixtures contained, in $0.8 \mathrm{ml}$.: $40 \mu$ mole L-arginine; $40 \mu$ mole sodium fumarate (replaced by water in controls); $20 \mu$ mole phosphate; and the amounts of protein indicated. Temperature $35^{\circ} ; \mathrm{pH} \mathbf{7 \cdot 5}$.

\begin{tabular}{|c|c|c|c|c|}
\hline Strain & Type of preparation & $\begin{array}{l}\text { Amount of } \\
\text { protein } \\
\text { (mg.) }\end{array}$ & $\begin{array}{l}\text { Incubation } \\
\text { period } \\
\text { (min.) }\end{array}$ & $\begin{array}{c}\text { Arginino- } \\
\text { succinate } \\
\text { formed } \\
(\mu \text { mole })\end{array}$ \\
\hline Wild type & Crude dialysed extract & $\mathbf{1} \cdot \mathbf{0}$ & 90 & 0.5 \\
\hline B317 & Crude dialysed extract & $1 \cdot 2$ & 180 & $<0.02^{*}$ \\
\hline B362 & Crude dialysed extract & $1 \cdot 3$ & 180 & $<0.02 *$ \\
\hline В368 & Crude dialysed extract & $1 \cdot 2$ & 180 & $<0.02 *$ \\
\hline B 370 & Crude dialysed extract & $1 \cdot 5$ & 180 & $<0.02 *$ \\
\hline Wild type & Partially purified & $1 \cdot 8$ & 45 & $\mathbf{3} \cdot \mathbf{5}$ \\
\hline B317 & Partially purified & $2 \cdot 1$ & 180 & $<0.02^{*}$ \\
\hline В362 & Partially purified & $2 \cdot 2$ & 180 & $<0.02 *$ \\
\hline B368 & Partially purified & $1 \cdot 3$ & 180 & $<0.02^{*}$ \\
\hline B370 & Partially purified & $2 \cdot 1$ & 180 & $<0.02^{*}$ \\
\hline
\end{tabular}

* Chromatogram obtained after three superimpositions of reaction mixture had no visible spot in the argininosuccinic acid region, and gave a scanning diagram the same as for the control without fumarate to within one scanner unit; $0.05 \times 10^{-3} \mathrm{M}$-argininosuccinate solution treated similarly gave a visible spot and a peak on the scanning diagram 5 units high.

\section{Table 3. Absence of inhibition of zoild-type argininosuccinase by inactive preparations from mutants}

Assay system as for Table 2. Mutant $\mathbf{B 3 6 2}$ used throughout. The figures show amounts of protein in $\mathrm{mg}$.

\begin{tabular}{|c|c|c|c|c|c|c|}
\hline \multirow[t]{3}{*}{ 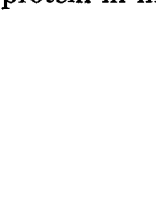 } & \multicolumn{4}{|c|}{ Enzyme preparation } & \multirow{4}{*}{$\begin{array}{c}\text { Period of } \\
\text { incubation } \\
\text { (min.) }\end{array}$} & \multirow{4}{*}{$\begin{array}{c}\text { Amount of } \\
\text { arginino- } \\
\text { succinic } \\
(\mu \text { mole })\end{array}$} \\
\hline & \multicolumn{2}{|c|}{$\begin{array}{c}\text { Crude dialysed } \\
\text { extract }\end{array}$} & \multicolumn{2}{|c|}{$\begin{array}{l}\text { Partially purified } \\
\text { preparation }\end{array}$} & & \\
\hline & \multicolumn{4}{|c|}{ Organism } & & \\
\hline Tube no. & Wild type & Mutant & Wild type & Mutant & & \\
\hline 1 & $1 \cdot 0$ & - & - & - & 120 & $2 \cdot 2$ \\
\hline $2,2 a^{*}$ & 0.5 & - & - & - & 120 & $1.2 \pm 0.08 \dagger$ \\
\hline 3, 3a* & 0.5 & $0 \cdot 6$ & - & - & 120 & $1.2 \pm 0.03 \dagger$ \\
\hline 4 & - & - & $1 \cdot 1$ & - & 40 & $3 \cdot 0$ \\
\hline $5,5 a$ & - & - & 0.55 & - & 40 & $1.6 \pm 0.05 \dagger$ \\
\hline $6,6 a$ & - & - & $0 \cdot 55$ & $0 \cdot 8$ & 40 & $1 \cdot 6 \pm 0.02 \dagger$ \\
\hline
\end{tabular}

The possibility that there was a potent inhibitor of argininosuccinase in the mutants appears to be ruled out, at least in the case of mutant B362, by experiments which showed that the addition of either crude or fractionated mutant extracts to corresponding wild-type preparations had no detectable effect on the argininosuccinase activity (Table 3). Furthermore, when mutant mycelium was added to a roughly equal quantity of wild-type mycelium, and the two were put through the whole extraction and fractionation procedure 
together, the recovery of argininosuccinase activity was similar to what would be expected if the mutant mycelium were neither contributing to, nor diminishing, the yield of enzyme (Fig. 5).

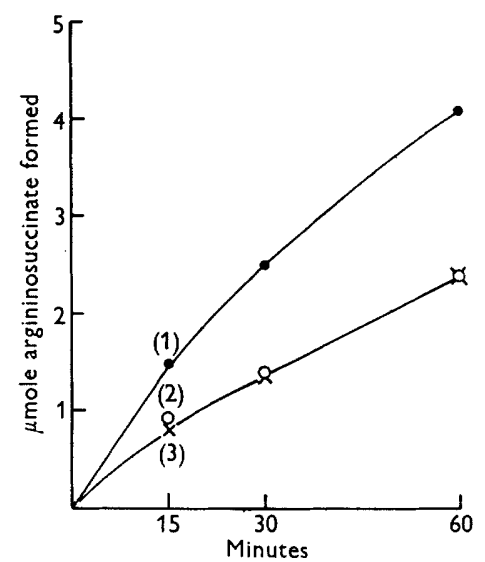

Fig. 5

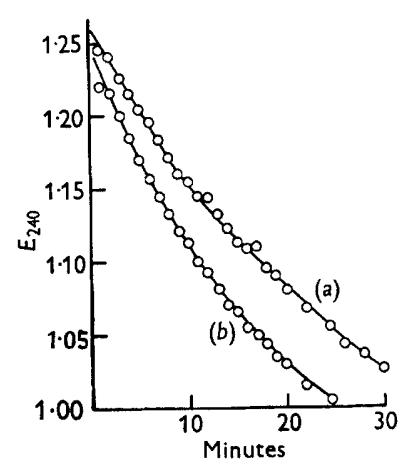

Fig. 6

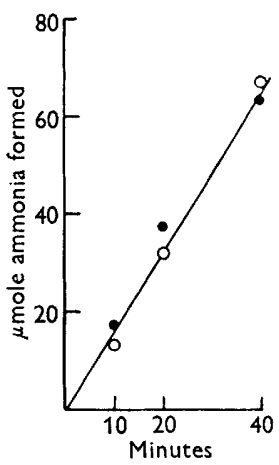

Fig. 7

Fig. 5. Formation of argininosuccinic acid by partially purified enzyme preparations from Neurospora crassa wild type (curves 1 and 2) and a mixture of approx. $60 \%$ wild type with $40 \%$ mutant B362 mycelium (curve 3). Digests contained, in 0.8 ml.: $40 \mu$ mole L-arginine hydrochloride; $40 \mu$ mole sodium fumarate; $24 \mu$ mole phosphate $(\mathrm{pH} 7 \cdot 4)$; and $1.2,0.6$ and $0.9 \mathrm{mg}$. protein in curves $1-3$, respectively. Temperature $35^{\circ}$.

Fig. 6. Fumarase activities of crude extracts of $(a)$ wild type, and $(b)$ mutant $B 362$. Spectrophotometer cells $(1 \mathrm{~cm}$.) contained, in $2.7 \mathrm{ml}$.: $50 \mu$ mole phosphate $(\mathrm{pH} 7.5) ; 0.5 \mu$ mole sodium fumarate (added at time 0 ); and 0.7 and $0.75 \mathrm{mg}$. protein in $(a)$ and $(b)$, respectively. Temperature approx. $18^{\circ}$.

Fig. 7. Arginase activities of crude extracts of wild type (O) and mutant B362 (O). Stoppered test tubes contained, in $1.5 \mathrm{ml}$ : $100 \mu$ mole phosphate $(\mathrm{pH} 7.5) ; 1 \mu$ mole $\mathrm{MnCl}_{2} ; 100 \mu$ mole L-arginine hydrochloride; $8 \cdot 3$ and $8.7 \mathrm{mg}$. protein from wild type and mutant, respectively, added at time 0 . After incubation at $35^{\circ}$ for the times indicated, tubes were heated briefly and urea was degraded to ammonia by the addition of $0.5 \mathrm{ml}$. of urease solution.

In one experiment the mutant 36703 , which resembles $B 317$ etc. in requiring arginine and failing to respond to citrulline, but which is the result of mutation in a different chromosome (Newmeyer, 1957), was found to produce about the same amount of argininosuccinase activity as the wild type.

\section{Other enzymes in mutant and wild-type strains}

The wild type and the mutant $\mathbf{B 3 6 2}$ produced rather similar amounts of arginase and fumarase (Figs. 6, 7). Thus the elimination of argininosuccinase in the mutant was not accompanied by any gross effect on other enzymes related to argininosuccinase in substrate specificity.

\section{DISCUSSION}

The data on the accumulation of citrulline and argininosuccinic acid by the mutants when supplied with citrulline are consistent with the hypothesis of a complete 'block' in the conversion of argininosuccinic acid to arginine. It 
seems probable that, when supplied with citrulline, the mutants convert it to argininosuccinic acid by combination with aspartic acid until the supply of the latter substance becomes limiting (probably through the observed depletion of the free amino-group pool of the mycelium), after which citrulline is accumulated as such. These effects of citrulline may account for its partial inhibition of growth of the mutants. The linear dependence of mutant growth on arginine supply at low arginine concentrations (Fig. 1) is also consistent with a complete inability to synthesize this substance. The observation that wildtype mycelium produces an active argininosuccinase which is apparently lacking in the mutants greatly strengthens the interpretation. There can be little doubt that argininosuccinic acid is a normal intermediate in arginine synthesis in Neurospora in spite of its failure to support growth of strain $\mathbf{3 6 7 0 3}$, which produces argininosuccinase. It is probable that argininosuccinic acid supplied in the medium fails to penetrate the cell (cf. Newmeyer, 1957).

This investigation appears to add to the growing number of cases both in Escherichia coli (Davis, 1955) and in Neurospora crassa (e.g. Yanofsky, 1952; Horowitz \& Fling, 1953; Fincham, 1954), where a mutation has resulted in the loss or alteration of a single enzyme. To this extent, the one gene-one enzyme hypothesis may be said to be receiving increasing support. However, although in the present study four mutants appeared to be biochemically indistinguishable, and all lacked the same enzyme, the genetic results given in the accompanying paper by Newmeyer (1957) suggest that they resulted from mutation at at least two distinct sites. B370 gave some wild-type ascospores in crosses with each of the other three mutants, and in the case of the $\mathrm{B370} \times \mathrm{B} 317$ cross it was shown that these wild types probably arose by crossing-over between two closely-linked loci. Thus the genetic basis of an enzyme may be a short chromosome segment, or complex locus, rather than a single gene in the sense of an indivisible unit.

This investigation was supported by a grant from the Nuffield Foundation, to which body we express our thanks.

\section{REFERENCES}

Archibatd, R. M. (1944). Determination of citrulline and allantoin and demonstration of citrulline in blood plasma. J. biol. Chem. 156, 121.

Davis, B. D. (1955). Nutritional and enzymatic studies on microbial mutants. In Perspectives and Horizons in Microbiology, ed. by S. A. Waksman. New Jersey: Rutgers University Press.

Fincham, J. R. S. (1954). Effects of a gene mutation in Neurospora crassa relating to glutamic dehydrogenase formation. J. gen. Microbiol. 11, 236.

Fincham, J. R. S. \& Boulter, A. B. (1956). Effects of amino acids on transaminase production in Neurospora crassa: evidence for four different enzymes. Biochem. $J .62,72$.

Honowitz, N. H. (1950). Biochemical genetics of Neurospora. Advanc. Genet. 3, 33.

Horowitz, N. H. \& Fling, M. (1953). Genetic determination of tyrosinase thermostability in Neurospora. Genetics, 38, 360.

Moore, S. \& Stein, W. H. (1948). Photometric ninhydrin method for use in the chromatography of amino acids. J. biol. Chem. 174, 367 . 
Newmeyer, D. (1957). Arginine synthesis in Neurospora crassa; genetic studies. J. gen. Microbiol. 16, 449.

RACKER, E. (1950). Spectrophotometric measurement of the enzymic formation of fumaric and cis-aconitic acids. Biochim. biophys. Acta, 4, 211.

Ratner, S., Anslow, W. P. Jun. \& Petrack, B. (1953). Biosynthesis of urea. VI. Enzymatic cleavage of argininosuccinic acid to arginine and fumaric acid. J. biol. Chem. 204, 115.

Ratner, S. \& Petrack, B. (1953a). Biosynthesis of urea. IV. Further studies on condensation in arginine synthesis from citrulline. J. biol. Chem. 200, 161.

Ratner, S. \& Petrack, B. $(1953 b)$. The mechanism of arginine synthesis from citrulline in kidney. J. biol. Chem. 200, 175.

Ratner, S., Petrack, B. \& Rochovansky, O. (1953). Biosynthesis of urea. V. Isolation and properties of argininosuccinic acid. J. biol. Chem. 204, 95.

SRB, A. M. \& Honowrtz, N. H. (1944). The ornithine cycle in Neurospora and its genetic control. J. biol. Chem. 154, 129.

YANOFSKY, C. (1952). The effects of gene change on tryptophan desmolase formation. Proc. nat. Acad. Sci., Wash. 38, 215.

(Received 18 October 1956) 